\title{
Balanço tendencial das dissertações e teses sobre dificuldades de aprendizagem (1987-2010)
}

José Geraldo Silveira Bueno

Professor Titular da Faculdade de Educação da PUC/SP

Angelita Mendes Ramos de Oliveira

Mestre em Educação pela PUC/SP

\section{Resumo}

O presente estudo, levado a efeito em 2012, teve por objetivo investigar as tendências da pesquisa educacional no que se refere aos chamados "distúrbios de aprendizagem". Por meio da análise de 183 resumos de teses e dissertações que abordaram as dificuldades de aprendizagem, depositadas no banco de teses da CAPES entre 1987 e 2010 e, com base nas contribuições de Williams (1980) e Bourdieu (2007), analisamos essas produções, das quais foram coletados os seguintes dados: Quem foram os autores institucionais? Quando se deram as defesas? Como as investigações foram produzidas? Por fim, procuramos recolher dados que pudessem evidenciar se a tendência de imputar o baixo rendimento escolar a pretensos "distúrbios de aprendizagem" prevaleceu durante todo o período investigado ou se a perspectiva crítica, representada pelos estudos de Patto (1999) e Collares \& Moysés (1996), passou a influir sobre essa produção.

Palavras-chave: Pesquisa educacional; Distúrbios de aprendizagem; Fracasso escolar.

\begin{abstract}
This paper, carried out in 2012, aimed to investigate trends in educational research in relation to so-called learning disabilities. Through the analysis of 183 abstracts of theses and dissertations that addressed learning difficulties, deposited in the Banco de Teses da CAPES between 1987 and 2010, based on the contributions of Williams (1980) and Bourdieu (2007), we analyzed these productions, which were collected the following data: Who were the authors institutional? When given the defenses? How the investigations were produced? Finally, we collect data that could show the tendency to attribute poor academic performance to alleged "learning disabilities" prevailed throughout the period investigated or if the critical perspective, represented by studies Patto (1999) and Collares \& Moyses (1996), has influenced on this production.
\end{abstract}

Keywords: Educational research; Learning disabilities; School failure.

Filosofia e Educação (Online), ISSN 1984-9605 - Volume 5, Número 2,

Outubro de 2013 


\section{Introdução}

U

ma das premissas básicas para o desenvolvimento de qualquer campo científico é o acúmulo do conhecimento produzido pelas pesquisas, acúmulo este que expressa a consistência desse determinado campo.

Dentro de tal perspectiva, esse trabalho teve por objetivo fundamental realizar um balanço bibliográfico das dissertações e teses produzidas no Brasil, no período de 1987 a 2010, e examinar as principais tendências de investigação que se ocuparam dos chamados “distúrbios de aprendizagem”.

A categoria "distúrbios de aprendizagem" explicativa do fracasso escolar assumiu papel preponderante após a segunda guerra mundial e foi divulgada por um conjunto de obras oriundas, principalmente, dos Estados Unidos, constituindo-se em uma das perspectivas mais aceitas no meio educacional brasileiro, especialmente entre os professores das séries iniciais do ensino obrigatório, nas décadas de 1970 a 1980.

No entanto, essa perspectiva explicativa sobre o baixo rendimento escolar, especialmente nas séries iniciais de alunos da escola básica, sofreu um conjunto de críticas expressas pelas obras de Patto (1999) e Collares \& Moysés (1996), a partir do final dos anos de 1980, estendendo-se até os dias atuais.

Apesar da emergência e disseminação desses estudos críticos, a vertente que imputa aos distúrbios de aprendizagem como fator explicativo do baixo rendimento escolar ainda permanece viva, tanto no imaginário dos docentes, quanto no campo acadêmico-científico.

No entanto, não se tem, até o momento, uma verdadeira dimensão de sua força, razão pela qual este trabalho buscou coletar, organizar, classificar e analisar as dissertações e teses defendidas no Brasil, por meio dos resumos divulgados no Banco de Teses da CAPES (Brasil. MEC. CAPES, 2012), no período integral coberto por esse banco, ou seja, de 1987 a 2010.

Uma das perspectivas teóricas que guiou esta investigação foi a do materialismo cultural de Raymond Williams (1980), que considera que as críticas às narrativas literárias - pautadas, segundo ele, em concepção 
restrita de forma e cânones estabelecidos - deve procurar estabelecer relações com os "meios" em que essa produção é produzida. Dizendo de outro modo, o autor propõe deslocar o modo de ler as obras, com prioridade para a análise dos contextos vividos por quem escreve.

Tal perspectiva permite compreender as características sociais e culturais que dão contornos às produções, ou seja, a crítica feita a partir do "exame das condições de uma prática, deve pautar-se na leitura diferenciada da tradição ou da produção criativa, buscando relacioná-las a dois momentos: o da referida produção e o da leitura analítica feita (Williams, 1980).

Assim, considerando a divulgação de pesquisas expressas em teses e dissertações como narrativas de cunho científico parte de um determinado campo, cabe analisar as formas de sua produção, em primeiro lugar, como produto de práticas sociais desenvolvidas no campo da pesquisa educacional, expressas pelos autores institucionais, a época de sua defesa e os procedimentos utilizados para suas construções.

Por outro lado, para a análise das tendências em relação a vertentes antagônicas sobre os distúrbios de aprendizagem como fator explicativo do baixo rendimento escolar, nos valemos das contribuições de Bourdieu (2007), em particular, a perspectiva crítica apresentada por ele sobre a teoria do dom como fator explicativo do baixo rendimento escolar de uma massa de alunos oriunda, fundamentalmente, das camadas populares, especialmente a crítica à democratização do ensino, expressa pela ampliação do acesso às camadas populares e pelos processos de exclusão branda utilizados pela escola atual.

Desta feita, com base nessas contribuições, esta investigação teve por objetivo elaborar um balanço tendencial da produção acadêmica sobre os distúrbios de aprendizagem, expressa pelas dissertações e teses defendidas no Brasil, no período de 1987 a 2010.

Para a coleta de dados, o Banco de Teses da Capes (Brasil. MEC. CAPES, 2012) foi selecionado como fonte, utilizando cinco descritores (fracasso escolar; dificuldades aprendizagem; distúrbios aprendizagem; transtornos de aprendizagem; rendimento escolar $<$ por meio dos quais foram 
encontrados 328 títulos, os quais, com a retirada das indicações duplicadas em mais de um descritor e pela leitura flutuante dos seus resumos, reduziuse a 183 títulos, que constituíram o universo analisado pela investigação.

\section{As vertentes teóricas explicativas do baixo rendimento escolar}

\subsection{As dificuldades de aprendizagem como fator explicativo do fracasso escolar}

Os estudos iniciais, compostos por obras fundamentalmente originárias dos Estados Unidos, se disseminaram pelo Brasil nas décadas de 1970 e 1980. Uma das primeiras obras americanas traduzidas, no Brasil, foi a de Schain, (1976), que informava sobre a literatura especializada produzida no seu país:

Uma revisão recente de vários estudos sobre distúrbios de leitura, nos Estados Unidos, mostrou que $15 \%$ das crianças em idade escolar, apresentam distúrbios de aprendizagem (La Veck, 1970); outros levantamentos variam de 5 a 30\% (de Hirsch, Jansky e Langfor, 1966). E, cada vez mais crianças com distúrbios de aprendizagem vêm sendo levadas a consultórios médicos, com objetivo de buscar subsídios para identificação dos fatores que estão contribuindo para o desempenho escolar deficiente (Schain, 1976, p. 1).

Este autor (Schain, 1976) apresentava diversos motivos de ordem patológica que impediriam o aluno de seguir o ritmo dos demais no que se refere à aprendizagem, tais como: dislexia, hiperatividade e disfunção cerebral mínima. Ele também citava os distúrbios ligados à fala que resultavam em fracasso escolar, os quais exigiriam, para seu diagnóstico, a participação de psicólogos e educadores, além do diagnóstico neurológico.

Dentro da mesma perspectiva, Ross (1979, p. 82-86) distinguia três tipos de problemas relacionados à ausência de aprendizagem do aluno, sendo eles: Distúrbios de Aprendizagem, as Dificuldades de aprendizagem e a Deficiência de Aprendizagem. 


\subsection{A visão crítica sobre as dificuldades de aprendizagem e o baixo rendimento escolar}

Como afirmamos no tópico anterior, tem se disseminado pelo país, desde a década de 70 até os nossos dias, um conjunto de estudos que explicam o baixo rendimento dos alunos por características intrínsecas em parcelas do alunado, caracterizadas como distúrbios, dificuldades ou deficiências de aprendizagem.

Conforme apontou as investigações realizadas por Collares e Moysés (1996) sobre o ponto de vista dos profissionais da escola sobre os casos de baixo rendimento escolar, ficou evidenciado que estes costumavam atribuir às crianças as causas de seu fracasso escolar, utilizando como argumento problemas de ordem biológica, psicológica e até mesmo problemas familiares advindos da pobreza e da desestruturação familiar:

Crianças não aprendem porque são pobres, porque são negras, porque são nordestinas, ou provenientes de zona rural; são imaturas, são preguiçosas; não aprendem porque seus pais são analfabetos, são alcoólatras, as mães trabalham fora, não ensinam aos filhos... (Collares e Moysés, 1996, p.26).

Corroborando com essas autoras, Souza (2008, p. 4) explica que

a análise do fracasso escolar tem como um de seus principais argumentos, o fato de que os problemas de aprendizagem incidem maciçamente sobre as crianças das classes populares e é sobre elas que durante décadas recaem as explicações a respeito dos chamados problemas de aprendizagem: ou porque apresentam problemas psicológicos, ou biológicos, ou orgânicos ou mais recentemente, socioculturais; bem como analisando o caráter ideológico e repleto de equívocos presentes nessas explicações, resultado de concepções preconceituosas a respeito do pobre e da pobreza no Brasil.

Conforme este último discurso a autora evidencia a concepção de que o complexo universo de questões institucionais, políticas, estruturais e de funcionamento presentes no contexto escolar devem constituir elementos desencadeadores para o fracasso dos alunos.

Filosofia e Educação (Online), ISSN 1984-9605 - Volume 5, Número 2, 
Apesar de todas as críticas aqui apresentadas, a imputação do fracasso escolar expresso pelo baixo rendimento escolar ainda tem se disseminado pelos sistemas de ensino. A pesquisa de Aparecido (2000), por exemplo, parte da premissa de que os materiais aos quais os professores da rede de ensino têm acesso se resumem a manuais. Examinando esses instrumentos, a autora supôs que os docentes faziam apropriações inadequadas dos seus conteúdos. Como não detinham conhecimento científico sobre os "reais distúrbios de aprendizagem", rotulavam como tal qualquer problema enfrentado pelo aluno com baixo rendimento.

Assim, diante de todo o material recolhido e analisado, a pesquisadora chegou à conclusão de que os manuais mais acessíveis ao público geral, em especial aos estudantes de magistério e professores em exercício, eram responsáveis pela disseminação dos processos de patologização do fracasso escolar. Isso ocorreria devido à absoluta falta de consistência teórica e a pretensa cientificidade dessa literatura. Dizendo de outro modo, a tese de que o problema residia numa apropriação inadequada do corpo docente, por falta de melhor formação, caiu por terra, já que o conhecimento disseminado entre os docentes não somente permitia, mas também favorecia a imputação ao aluno das causas do seu baixo rendimento escolar.

Partindo da mesma perspectiva, Rodrigues (2009) selecionou como fonte de dados as fichas de encaminhamentos, preenchidas pelas professoras dos alunos das escolas municipais que, por apresentarem baixo rendimento escolar, foram enviados ao Núcleo de Apoio e Atendimento Interdisciplinar de um município situado na grande São Paulo.

Os resultados de sua investigação demonstram que os encaminhamentos tinham como principal queixa os problemas de aprendizagem e, de maneira reduzida, os problemas de comportamento e, ainda com menos incidência, os problemas de ordem emocional, familiar e social. Porém, o achado mais importante da pesquisa de Rodrigues (2009), para os fins da presente investigação, foi a própria estruturação da ficha de encaminhamento, elaborada pela equipe especializada do Núcleo de Apoio e Atendimento Interdisciplinar, a qual induzia o professor a imputar ao aluno patologias relacionadas ao seu rendimento escolar ou aos seus problemas 
familiares, uma vez que não havia um item sequer que se voltasse para as questões didáticas e de práticas docentes como possíveis responsáveis pela defasagem do aluno.

Concluindo este capítulo, podemos verificar que, apesar do conjunto de críticas direcionadas ao conceito "distúrbios de aprendizagem”, seu uso é perceptível tanto nas concepções dos professores, demonstradas pelos trabalhos de Aparecido (2000) e Rodrigues (2009), quanto nos meios acadêmico conforme pôde ser constatado através da leitura dos resumos das teses e dissertações que serão objetos do próximo capítulo.

\subsection{Os autores institucionais e os períodos de produção}

As primeiras questões a serem respondidas, tal como indicado na introdução, referem-se aos autores institucionais que investigaram os distúrbios de aprendizagem e que resultaram em dissertações e teses defendidas, bem como a sua distribuição anual, no período de 1987 a 2010. Para tanto, apresentamos os dados sobre as instituições onde foram defendidas, as áreas de conhecimento, programas, níveis de titulação alcançado e o ano de cada defesa.

A tabela 1 apresenta a distribuição das instituições em que as dissertações e teses foram defendidas.

Filosofia e Educação (Online), ISSN 1984-9605 - Volume 5, Número 2, 
Tabela 1

Instituições em que foram defendidas as dissertacões e teses sobre distúrbios de aprendizagem $(1987 / 2010)$

\begin{tabular}{|c|c|c|c|c|c|}
\hline Instituição & $\mathrm{N}^{\mathbf{0}}$ & $\%$ & Instituição & $\mathbf{N}^{\mathbf{0}}$ & $\%$ \\
\hline USP & 18 & 9,8 & FURG & 1 & 0,5 \\
\hline UFSCar & 17 & 9,3 & PUCGO & 1 & 0,5 \\
\hline PUCSP & 12 & 6,5 & PUCPR & 1 & 0,5 \\
\hline UNICAMP & 10 & 5,5 & UCP & 1 & 0,5 \\
\hline PUCRS & 6 & 3,3 & UCPel & 1 & 0,5 \\
\hline UFMG & 6 & 3,3 & UEL & 1 & 0,5 \\
\hline UFPE & 6 & 3,3 & UENF & 1 & 0,5 \\
\hline FURB & 5 & 2,7 & UFAM & 1 & 0,5 \\
\hline UFF & 5 & 2,7 & UFJF & 1 & 0,5 \\
\hline UnB & 5 & 2,7 & UFMS & 1 & 0,5 \\
\hline UNIMEP & 5 & 2,7 & UFPel & 1 & 0,5 \\
\hline UERJ & 4 & 2,2 & UFSM & 1 & 0,5 \\
\hline UFRGS & 4 & 2,2 & UGF & 1 & 0,5 \\
\hline UFSC & 4 & 2,2 & UMESP & 1 & 0,5 \\
\hline $\begin{array}{l}\text { UNESP- } \\
\text { Marília }\end{array}$ & 4 & 2,2 & UNESA & 1 & 0,5 \\
\hline $\begin{array}{l}\text { PUC- } \\
\text { Camp }\end{array}$ & 3 & 1,7 & $\begin{array}{l}\text { UNESP - } \\
\text { Araraquara }\end{array}$ & 1 & 0,5 \\
\hline $\mathrm{UCB}$ & 3 & 1,7 & $\begin{array}{l}\text { UNESP - } \\
\text { Assis }\end{array}$ & 1 & 0,5 \\
\hline UEM & 3 & 1,7 & UNIFESP & 1 & 0,5 \\
\hline UFC & 3 & 1,7 & UNIJUÍ & 1 & 0,5 \\
\hline UFES & 3 & 1,7 & CUML & 1 & 0,5 \\
\hline UFMT & 3 & 1,7 & CURR & 1 & 0,5 \\
\hline UFU & 3 & 1,7 & UNISO & 1 & 0,5 \\
\hline UPM & 3 & 1,7 & UNIUBE & 1 & 0,5 \\
\hline USF & 3 & 1,7 & UNIVALI & 1 & 0,5 \\
\hline PUCMG & 2 & 1,2 & UNIVAP & 1 & 0,5 \\
\hline UFPA & 2 & 1,2 & USJT & 1 & 0,5 \\
\hline UFPR & 2 & 1,2 & USC & 1 & 0,5 \\
\hline $\begin{array}{l}\text { UFRJ } \\
\text { UNESP - }\end{array}$ & 2 & 1,2 & UNISAL & 1 & 0,5 \\
\hline Rio Claro & 2 & 1,2 & UNISA & 1 & 0,5 \\
\hline UNOESTE & 2 & 1,2 & UCDB & 1 & 0,5 \\
\hline CUML & 1 & 0,5 & UFGO & 1 & 0,5 \\
\hline FIOCRUZ & 1 & 0,5 & Total & 183 & 100 \\
\hline
\end{tabular}

Fonte:Banco de Teses - CAPES

Filosofia e Educação (Online), ISSN 1984-9605 - Volume 5, Número 2, 
Verificamos, de um lado, que, aproximadamente, 1/3 da produção $(31,1 \%)$ pertence a instituições situadas no estado de São Paulo (USP, UFSCar, PUC/SP e UNICAMP), destacando-se as duas primeiras, cada uma delas com praticamente $10 \%$ da produção. Além disso, duas são universidades estaduais, o que mostra a força dessas instituições na pesquisa educacional.

É relevante, ainda, destacar que, dentre as quatro primeiras posições, apenas a PUC de São Paulo é uma instituição privada e, dos 11 trabalhos defendidos nesta universidade, três tiveram um único orientador.

A análise revela ainda, que há grande dispersão entre essas produções, uma vez que trinta delas foram defendidas em número igual de instituições, ou seja, uma produção por instituição, o que parece demonstrar interesse esporádico, não oriundo de grupos de pesquisa que se dedicam a esse tema.

Ainda referente a este bloco, a próxima tabela evidencia a quantidade de estudos distribuídos pelas diferentes áreas, ou seja, os campos de conhecimento que se voltaram para os distúrbios de aprendizagem.

Tabela 2

Áreas de conhecimento dos programas que geraram teses e dissertações sobre distúrbios de aprendizagem $(1987 / 2010)$

\begin{tabular}{|c|c|c|}
\hline Cursos & $\mathbf{N}^{0}$ & $\%$ \\
\hline Educação & 125 & 68,4 \\
\hline Psicologia & 31 & 16,9 \\
\hline Saúde & 15 & 8,3 \\
\hline Linguística & 4 & 2,7 \\
\hline Ciências biológicas & 3 & 1,6 \\
\hline Políticas sociais & 2 & 1,1 \\
\hline Educação física & 1 & 0,5 \\
\hline Filosofia & 1 & 0,5 \\
\hline Química & 1 & 0,5 \\
\hline Total & 183 & 100 \\
\hline
\end{tabular}

Fonte: Banco de Teses - CAPES

Apesar de verificarmos, como esperado, que a educação é a área mais destacada em termos de estudos sobre os distúrbios de aprendizagem $(68,3 \%)$, as outras duas mais incidentes foram a psicologia $(16,9 \%)$ e a saúde $(8,9 \%)$.

Filosofia e Educação (Online), ISSN 1984-9605 - Volume 5, Número 2, 
Estes dois últimos resultados parecem apontar para a questão da "terceirização dos problemas referentes ao baixo rendimento escolar", ou seja, o próprio fato de atribuir uma doença ao aluno que não aprende justifica o interesse dos profissionais das áreas da saúde e da psicologia em tentar analisar esse processo.

Apesar da baixa incidência nas outras áreas, os dados demonstram que outros especialistas, como linguistas, biólogos e professores de educação física também se voltam à investigação desses distúrbios.

A próxima tabela revela o nível acadêmico dos pesquisadores que se ocupam da referida temática.

Tabela 3

Distribuição de mestrados e doutorados (1987-2010)

\begin{tabular}{lc}
\hline Grau & $\mathbf{N}^{\mathbf{0}}$ \\
\hline Mestrado Acadêmico & 156 \\
Doutorado & 21 \\
Mestrado Profissional & 6 \\
\hline Total & $\mathbf{1 8 3}$ \\
\hline Fonte: Banco de Teses - CAPES
\end{tabular}

É possível verificar que a imensa maioria dos estudos foi realizada no âmbito do mestrado acadêmico, a minoria no mestrado profissionalizante e uma quantidade um pouco superior a este último tem origem nos cursos de doutorado.

$\mathrm{Na}$ análise, também podemos considerar o tempo de duração dos cursos de mestrado e doutorado no Brasil, já que o tempo médio do primeiro é de 24 (vinte e quatro) meses e o do último, de 48 (quarenta e oito) meses.

A baixa incidência de teses de doutorado em relação às dissertações de mestrado pode significar que, em nível mais elevado de titulação, as pesquisas sobre os distúrbios de aprendizagem como fator explicativo do fracasso escolar estão, paulatinamente, diminuindo em quantidade (voltaremos a essa hipótese no final deste capítulo).

A quarta tabela relativa a este tópico mostra a distribuição da produção no período coberto pelos estudos. 
Tabela 4

Ano de defesa das dissertações e teses (1987-2010)

\begin{tabular}{|c|c|c|}
\hline Ano & $\mathrm{N}^{\mathbf{0}}$ & $\%$ \\
\hline 1987 & 1 & 0,5 \\
\hline 1988 & 2 & 1,1 \\
\hline 1989 & 0 & 0 \\
\hline 1990 & 2 & 1,1 \\
\hline 1991 & 0 & 0 \\
\hline 1992 & 4 & 2,2 \\
\hline 1993 & 6 & 3,3 \\
\hline 1994 & 0 & 0 \\
\hline 1995 & 4 & 2,2 \\
\hline 1996 & 4 & 2,2 \\
\hline 1997 & 9 & 4,9 \\
\hline 1998 & 8 & 4,4 \\
\hline 1999 & 12 & 6,6 \\
\hline 2000 & 3 & 1,6 \\
\hline 2001 & 10 & 5,5 \\
\hline 2002 & 8 & 4,4 \\
\hline 2003 & 15 & 8,2 \\
\hline 2004 & 12 & 6,6 \\
\hline 2005 & 13 & 7,1 \\
\hline 2006 & 7 & 3,8 \\
\hline 2007 & 20 & 10,9 \\
\hline 2008 & 14 & 7,6 \\
\hline 2009 & 15 & 8,2 \\
\hline 2010 & 14 & 7,6 \\
\hline Total & 183 & 100 \\
\hline
\end{tabular}

Fonte: Banco de Teses - CAPES

Com base na tabela n. 4 , verificamos que a incidência destes estudos está distribuída em dois períodos: o primeiro, de 1987 a 1996, e o segundo, de 1997 a 2010. A tabela também informa que 87,4\% destes trabalhos foram defendidos neste último período, enquanto que, no primeiro, foram apenas $12,6 \%$.

A baixa incidência do tema "dificuldades de aprendizagem", no primeiro período, em relação ao segundo, pode expressar o impacto que a perspectiva crítica causou na produção sobre fatores relacionados ao baixo rendimento escolar. Ao investigarem esses distúrbios, Patto (1999), assim

Filosofia e Educação (Online), ISSN 1984-9605 - Volume 5, Número 2, 
como Collares e Moysés (1996) estabeleceram um conjunto de críticas sobre o caráter científico dessa classificação, que parece ter repercutido nos meios acadêmicos.

No entanto, a partir do final da década de 1990, os estudos sobre distúrbios de aprendizagem recrudesceram, provavelmente impulsionados pelas reformas educacionais que surgiram após a promulgação da Lei de Diretrizes e Bases da Educação Nacional (BRASIL, 1996). A implementação de políticas de redução da repetência/evasão, como o regime de progressão continuada e o sistema de ciclos, eliminou a face mais evidente da seletividade da escola e permitiu o incremento de alunos com baixo rendimento escolar, que se disseminou praticamente por todo o ensino fundamental.

É provável, então, que o impacto causado pela perspectiva crítica sobre a produção acadêmico-científica especializada no baixo rendimento escolar tenha sido temporário. Os estudos recrudesceram, especialmente, na primeira década do século XXI, fato que pode ser melhor verificado a partir da análise dos temas específicos das produções (Tabelas 10 e 11).

\subsection{Os modos de investigação}

A partir deste tópico, voltamos nossa atenção às formas pelas quais as dissertações e teses investigaram os distúrbios de aprendizagem como fator explicativo do baixo rendimento escolar.

A tabela 5 apresenta a distribuição das abordagens escolhidas pelos pesquisadores.

Tabela 5

Distribuição das abordagens utilizadas nas dissertações e teses sobre distúrbios de aprendizagem (1987-2010)

\begin{tabular}{lcc}
\hline Abordagem & $\mathbf{N}^{\mathbf{0}}$ & $\mathbf{\%}$ \\
\hline Qualitativa & 159 & 87 \\
Quanti-qualitativa & 22 & 12 \\
Quantitativa & 2 & 01 \\
\hline Total & $\mathbf{1 8 3}$ & $\mathbf{1 0 0}$ \\
\hline \multicolumn{1}{c}{ Fonte: Banco de Teses - CAPES } &
\end{tabular}

Filosofia e Educação (Online), ISSN 1984-9605 - Volume 5, Número 2, 
A abordagem qualitativa de pesquisa correspondeu à maior parte delas, conforme destacado acima, atingindo $87 \%$ do total.

É paradoxal a escassez de estudos quantitativos, quando se verifica que a caracterização dos estudos sobre os distúrbios de aprendizagem, como um dos fatores primordiais para o baixo rendimento escolar, define a diferença de desempenho entre esses alunos e os considerados normais em termos de incidência, ou seja, os mais graves são aqueles que, por exemplo, no aprendizado da leitura e da escrita, mais se distanciam dos padrões esperados para a idade e série.

A próxima tabela apresenta os tipos de pesquisa desenvolvidos.

Tabela 6

Distribuição dos tipos de pesquisa utilizadas nas dissertações e teses sobre distúrbios de aprendizagem (1987-2010)

\begin{tabular}{lcc}
\hline Tipo & $\mathbf{N}^{\mathbf{0}}$ & $\mathbf{\%}$ \\
\hline Campo & 167 & 91,3 \\
Teórica & 10 & 5,5 \\
Bibliográfica & 5 & 2,7 \\
Documental & 1 & 0,5 \\
\hline \multicolumn{1}{c}{ Total } & $\mathbf{1 8 3}$ & $\mathbf{1 0 0}$ \\
\hline
\end{tabular}

Fonte: Banco de Teses - CAPES

Estes dados evidenciam a mesma discrepância destacada na tabela anterior, ou seja, 91,3\% dos pesquisadores realizaram seus estudos por meio de pesquisas de campo, restando apenas 8,7\% para as demais metodologias, destacando-se entre essas a pesquisa teórica, que representou 5,5\% do total das investigações. Supomos, assim, que as abordagens críticas não propiciaram a disseminação de estudos sobre os princípios teóricos que estabeleceram os critérios para definição dos distúrbios de aprendizagem (Cf. Aparecido, 2000).

Considerando a perspectiva de análise revelada por Williams (1980) e, de acordo com as abordagens de Patto (1999) e Collares e Moysés (1996), podemos considerar que a pesquisa de campo parece refletir a permanência de uma perspectiva medicalizadora do fracasso escolar expresso pelo baixo rendimento dos alunos. 
A tabela 7 apresenta os dados sobre os procedimentos utilizados nas investigações.

Tabela 7

Distribuição dos procedimentos de coleta de dados nas dissertações e teses sobre distúrbios de aprendizagem (1987-2010)

\begin{tabular}{lcc}
\hline \multicolumn{1}{c}{ Procedimento } & $\mathbf{N}^{\mathbf{0}}$ & $\mathbf{\%}$ \\
\hline Entrevista & 75 & 30,2 \\
Observação & 60 & 24,2 \\
Testagem & 36 & 14,5 \\
Questionário & 27 & 10,9 \\
Documentação & 15 & 6,0 \\
Dados estatísticos & 2 & 0,8 \\
Outro & 18 & 7,4 \\
Não designa & 15 & 6,0 \\
\hline TOTAL & $\mathbf{2 4 8}^{*}$ & $\mathbf{1 0 0}$ \\
\hline
\end{tabular}

Fonte: Banco de Teses - CAPES

(*) O número de procedimentos é superior ao das produções porque muitos utilizaram mais de um procedimento.

Pode-se verificar, nesta tabela, a alta incidência de instrumentos como a entrevista e a observação na realização dos trabalhos, incidência encontrada em outros balanços sobre escolarização, como os de Marin, Bueno e Sampaio (2005) e Marin, Bueno e Penna (2011).

Neste caso, entretanto, a existência de trinta e seis pesquisas - que utilizaram os testes como instrumentos de coleta de dados - parecem revelar incompatibilidade, porque o número reduzido de pesquisas quantitativas pressupõe que nem todos estes testes foram tratados por critérios de incidência estatística, já que apenas dois estudos utilizaram esse tipo de informação.

Embora o questionário também apresente incidência relativamente alta, o fato de os dados neles colhidos também não serem trabalhados por meio de critérios estatísticos parece sintomático, uma vez que esse instrumento poderia favorecer o seu uso.

\subsection{Os objetos de investigação}

Nas três tabelas a seguir, nosso foco volta-se para os temas das pesquisas, procurando identificar as abordagens centradas nos distúrbios de aprendizagem como fator explicativo do baixo rendimento escolar e as que,

Filosofia e Educação (Online), ISSN 1984-9605 - Volume 5, Número 2, 
ao contrário, adotaram uma perspectiva crítica desses distúrbios como fator explicativo do fracasso escolar.

A tabela 8 apresenta essa distinção em relação às instituições nas quais as dissertações e teses foram defendidas.

Tabela 8

Distinção entre as produções que se centraram nos distúrbios de aprendizagem e as que adotaram perspectiva crítica, por instituição onde foram defendidas (1987-2010)

\begin{tabular}{|c|c|c|c|c|c|c|c|c|c|}
\hline TES/CT & DA & FE & N/D & TOTAL & IES/CT & DA & $\mathbf{F E}$ & $\mathbf{N} / \mathbf{D}$ & TOTAL \\
\hline USP & $\pi$ & 7 & 0 & 18 & FGV & 0 & $T$ & 0 & 1 \\
\hline UFSCar & 9 & 8 & 0 & 17 & FURG & 0 & 1 & 0 & 1 \\
\hline $\mathrm{PUC} / \mathrm{SP}$ & 6 & 5 & 1 & 12 & $\mathrm{PUC} / \mathrm{GO}$ & 1 & 0 & 0 & 1 \\
\hline UNICAMP & 6 & 4 & 0 & 10 & $\mathrm{PUC} / \mathrm{PR}$ & 0 & 1 & 0 & 1 \\
\hline PUC/RS & 5 & 1 & 0 & 6 & $\mathrm{UCP}$ & 1 & 0 & 0 & 1 \\
\hline UFMG & 2 & 4 & 0 & 6 & UEL & 0 & 1 & 0 & 1 \\
\hline UFPE & 2 & 4 & 0 & 6 & UENF & 0 & 1 & 0 & 1 \\
\hline FURB & 4 & 1 & 0 & 5 & UFAM & 1 & 0 & 0 & 1 \\
\hline UFF & 4 & 1 & 0 & 5 & UFJF & 0 & 1 & 0 & 1 \\
\hline UnB & 3 & 2 & 0 & 5 & UFMS & 0 & 1 & 0 & 1 \\
\hline UNIMEP & 4 & 1 & 0 & 5 & UFPEL & 0 & 1 & 0 & 1 \\
\hline UERJ & 2 & 2 & 0 & 4 & UFSM & 1 & 0 & 0 & 1 \\
\hline ,UFRGS & 2 & 2 & 0 & 4 & UGF & 1 & 0 & 0 & 1 \\
\hline UFSC & 2 & 2 & 0 & 4 & UMESP & 1 & 0 & 0 & 1 \\
\hline UNESP-Mar & 1 & 3 & 0 & 4 & UNESA & 0 & 1 & 0 & 1 \\
\hline PUC/Camp & 2 & 0 & $T$ & 3 & UNESP-AR & 1 & 0 & 0 & 1 \\
\hline UCB & 2 & 1 & 0 & 3 & UNESP-Assis & 1 & 0 & 0 & 1 \\
\hline UEM & 2 & 1 & 0 & 3 & UNIFESP & 1 & 0 & 0 & 1 \\
\hline UFC & 1 & 2 & 0 & 3 & UNIRITTER & 0 & 1 & 0 & 1 \\
\hline UFMT & 1 & 2 & 0 & 3 & UNISO & 0 & 1 & 0 & 1 \\
\hline UFES & 1 & 2 & 0 & 3 & UNIUBE & 0 & 1 & 0 & 1 \\
\hline UFU & 1 & 2 & 0 & 3 & UNIVALI & 0 & 1 & 0 & 1 \\
\hline UPM & 2 & 1 & 0 & 3 & UNIVAP & 1 & 0 & 0 & 1 \\
\hline USF & 1 & 2 & 0 & 3 & USJT & 0 & 1 & 0 & 1 \\
\hline PUC/MG & 0 & 2 & 0 & 2 & USC & 0 & 1 & 0 & 1 \\
\hline UFPA & 1 & 1 & 0 & 2 & UNISAL & 1 & 0 & 0 & 1 \\
\hline UFPR & 2 & 0 & 0 & 2 & UNISA & 1 & 0 & 0 & 1 \\
\hline UFRJ & 1 & 1 & 0 & 2 & UCDB & 1 & 0 & 0 & 1 \\
\hline UNESP-RC & 1 & 1 & 0 & 2 & UFG & 1 & 0 & 0 & 1 \\
\hline UNOESTE & 1 & 1 & 0 & 2 & UCPel & 0 & 1 & 0 & 1 \\
\hline CUML & 0 & 1 & 0 & 1 & UNIJUÍ & 0 & 1 & 0 & 1 \\
\hline FIOCRUZ & 0 & 1 & 0 & 1 & TOTAL & 96 & 85 & 2 & 183 \\
\hline
\end{tabular}

Filosofia e Educação (Online), ISSN 1984-9605 - Volume 5, Número 2, Outubro de 2013 
Fonte: Banco de Teses - CAPES

Legenda: DA: distúrbios de aprendizagem; FE: Fracasso escolar; N/D: Não discriminou.

$\mathrm{O}$ primeiro dado a ser destacado refere-se à quantidade total dos estudos em cada uma das perspectivas: enquanto 96 trabalhos adotaram a perspectiva dos distúrbios de aprendizagem como fator explicativo do fracasso escolar (52\%), 85 adotaram uma perspectiva crítica (46\%).

Nas quatro primeiras instituições, em termos de incidência de estudos (USP, UFSCar, PUC/SP e UNICAMP) - embora haja relativo equilíbrio entre aquelas que analisam o baixo rendimento escolar pela óptica dos distúrbios de aprendizagem e as que procuram investigar esse baixo rendimento por outros fatores relacionados ao fracasso escolar -, há uma ligeira vantagem para os primeiros, até mesmo na USP, onde atuava a Prof ${ }^{\mathrm{a}}$ Maria Helena Souza Patto, cujos estudos são considerados os fundadores da perspectiva crítica.

Nas IES com incidência menos expressiva (em verde na tabela), podemos constatar que a PUC/RS, a FURB, a UFF e a UNIMEP apresentam incidência mais expressiva nos estudos que adotam a perspectiva dos distúrbios de aprendizagem como fator explicativo do baixo rendimento escolar, enquanto que na UFMG, UFPE e UNESP-Mar a incidência mais expressiva foi a de estudos que adotaram uma perspectiva crítica. Nas demais, ocorreu um equilíbrio entre as duas perspectivas de análise.

Quanto às demais instituições, mesmo não sendo possível a efetiva análise das tendências em relação às perspectivas, cabe-nos apenas afirmar que, entre as instituições que realizaram de dois a três trabalhos (em rosa na tabela), na PUC/Camp e UFPR foram defendidas duas produções cada, com enfoque nos distúrbios de aprendizagem, e com enfoque em outros fatores relacionados ao fracasso escolar, somente na UFMG. Nas demais instituições, as produções se distribuíram entre as duas perspectivas.

No entanto, de modo geral, podemos verificar que, do total dessas últimas instituições (48), 19 (dezenove) adotaram a perspectiva dos distúrbios de aprendizagem, em 4 (quatro) a produção se distribuiu entre as duas perspectivas e em 25 (vinte e cinco) dominou a perspectiva crítica. 
Esses últimos dados mostram que, embora a perspectiva dos distúrbios de aprendizagem ainda permaneça, as instituições em que foram defendidos os trabalhos sob a perspectiva crítica apresentaram ligeira superioridade (38 contra 33), o que pode estar revelando uma mudança de enfoque a ser estudada em trabalhos posteriores.

De posse dos dados referente às tendências institucionais em relação a essas duas vertentes, evidenciamos, na tabela 9, as áreas nas quais as teses e dissertações foram defendidas.

Tabela 9

Distinção entre as produções que se centraram nos distúrbios de aprendizagem e as que adotaram perspectiva crítica, área onde os programas estavam inseridos (1987-2010)

\begin{tabular}{lcccc}
\hline $\begin{array}{c}\text { Programa/Camp } \\
\text { o temático }\end{array}$ & $\begin{array}{c}\text { Distúrbios de } \\
\text { aprendizage } \\
\text { m }\end{array}$ & $\begin{array}{c}\text { Fracasso } \\
\text { escolar }\end{array}$ & $\begin{array}{c}\text { Não } \\
\text { discrimin } \\
\text { a }\end{array}$ & TOTAL \\
\hline Educação & 57 & 67 & 1 & 125 \\
Psicologia & 23 & 7 & 1 & 31 \\
Saúde & 11 & 4 & 0 & 15 \\
Linguística & 2 & 2 & 0 & 4 \\
Ciências & 2 & 1 & 0 & 3 \\
biológicas & 0 & 2 & 0 & 2 \\
Políticas sociais & 1 & 0 & 0 & 1 \\
Filosofia & 0 & 1 & 0 & 1 \\
Química & 0 & 1 & 0 & 1 \\
Educação física & $\mathbf{9 6}$ & $\mathbf{8 5}$ & $\mathbf{2}$ & $\mathbf{1 8 3}$ \\
\hline \multicolumn{1}{c}{ TOTAL } & $\mathbf{9 6}$ & & &
\end{tabular}

Fonte: Banco de Teses - CAPES

Como podemos observar, a produção na área da educação é bastante equilibrada entre as duas perspectivas, demonstrando que a abordagem centrada nos distúrbios e a abordagem crítica são presentes, não devendo ser secundarizado o fato de que, embora por pequena margem, a perspectiva crítica seja a mais incidente.

Apesar de apresentarem reduzida participação, percebemos que as pesquisas desenvolvidas nas áreas de psicologia e saúde continuam privilegiando o enfoque dos distúrbios de aprendizagem como fator explicativo para o fracasso escolar. A tendência, conforme Moysés (2008), já se fazia presente entre os séculos XIX e XX.

Se na área da medicina esta maior incidência já era esperada, dado o caráter organicista de grande parte desses estudos, surpreende-nos a 
incidência três vezes maior dessa tendência na área de psicologia, berço acadêmico da perspectiva crítica.

Quanto às demais áreas, mesmo com uma incidência irrisória, elas parecem mostrar um equilíbrio entre as duas perspectivas.

As últimas duas tabelas estão relacionadas aos dados da distribuição das dissertações e teses centradas nos distúrbios de aprendizagem por tema específico abordado, dados estes que estão expostos em duas tabelas separadamente: dos 183 trabalhos, 68 estão relacionados ao campo temático distúrbios de aprendizagem (tabela 11) e 47 trabalhos se referem ao campo temático fracasso escolar (tabela 12). Os demais trabalhos (68) não disponibilizaram tal informação.

\section{Tabela 10}

Distribuição dos temas específicos abordados no campo temático distúrbios de aprendizagem (1987-2010)

\begin{tabular}{lcc}
\hline \multicolumn{1}{c}{ Tema específico } & $\mathbf{N}^{\mathbf{0}}$ & $\mathbf{\%}$ \\
\hline Dificuldade/distúrbio/problema de aprendizagem & 44 & 64,7 \\
Comportamento & 9 & 13,2 \\
Dislexia, TDAH & 6 & 8,8 \\
Problema auditivo & 3 & 4,5 \\
Atraso no desenvolvimento da linguagem & 2 & 2,9 \\
Epilepsia & 2 & 2,9 \\
Sintomas depressivos & 1 & 1,5 \\
Desnutrição & 1 & 1,5 \\
\hline \multicolumn{1}{c}{$\quad$ Total } & $\mathbf{6 8}$ & $\mathbf{1 0 0}$ \\
\hline
\end{tabular}

Fonte: Banco de Teses - CAPES

Verificamos, assim, que a grande incidência refere-se, genericamente, a esses distúrbios. Dizendo de outro modo, para esses trabalhos, a incorporação do distúrbio de aprendizagem, considerado como aquele que, apesar de nenhuma anormalidade sensorial, física, mental e social evidente (tal como os teóricos apresentados no capítulo 1 os definem), é responsável pelo baixo rendimento escolar.

Outro aspecto a ser destacado é o número significativo de alunos considerados portadores de distúrbios de aprendizagem cuja causa é o "comportamento", o que parece evidenciar uma fragilidade teórica ainda mais marcante que a dos anteriores. 
A distribuição entre quadros mais específicos é tão pequena que impede uma análise mais detalhadas das suas tendências.

$\mathrm{Na}$ tabela a seguir destacamos a quantidade de temas específicos cujo campo temático foi o fracasso escolar, campo que merece comentários a respeito, a exemplo dos problemas de aprendizagem.

Tabela 11

Distribuição dos temas específicos abordados no campo temático Fracasso escolar (1987-2010)

\begin{tabular}{|c|c|c|c|c|}
\hline Consolidado & Tema específico & $\underset{\mathbf{o}}{\mathbf{N}}$ & $\%$ & $\begin{array}{l}\% \\
\mathrm{C}\end{array}$ \\
\hline \multirow{5}{*}{$\begin{array}{l}\text { Indicadores de } \\
\text { problemas }\end{array}$} & Repetência/Multirrepetência & 19 & $\begin{array}{c}40 \\
4\end{array}$ & \multirow{5}{*}{$\begin{array}{c}68, \\
1\end{array}$} \\
\hline & Rendimento escolar & 4 & 8,5 & \\
\hline & Distorção idade-série & 2 & 4,3 & \\
\hline & Avaliação & 4 & 8,5 & \\
\hline & Alfabetização/Leitura & 3 & 6,4 & \\
\hline \multirow{3}{*}{$\begin{array}{l}\text { Programas/projeto } \\
\text { S }\end{array}$} & $\begin{array}{l}\text { Recuperação paralela/ Classe de } \\
\text { aceleração }\end{array}$ & 5 & $\begin{array}{c}10 \\
6\end{array}$ & \multirow{3}{*}{$\begin{array}{c}25 \\
5\end{array}$} \\
\hline & Alfabetização com abordagem fônica & 4 & 8,5 & \\
\hline & Progressão continuada & 3 & 6,4 & \\
\hline \multirow{3}{*}{ Outros focos } & Formação continuada de professores & 2 & 4,3 & \multirow{3}{*}{6,4} \\
\hline & EJA & 1 & 2,1 & \\
\hline & Total & 47 & 100 & \\
\hline
\end{tabular}

Fonte: Banco de Teses - CAPES

Legenda $-\% \mathrm{C}=$ percentual consolidado.

Os dados desta tabela indicam que os pesquisadores da perspectiva crítica analisaram aspectos relacionados aos casos de repetência e multirrepetência em mais de $1 / 3$ dos trabalhos, muito superior ao segundo tema mais incidente (Recuperação paralela/Classes de aceleração), com apenas 5 (cinco) produções no período. As demais produções tiveram incidência ainda mais baixa.

Se agregarmos esses trabalhos em termos de temas específicos mais consolidados, veremos que os indicadores de problemas relativos ao fracasso escolar somam $68,1 \%$. Os que se ocuparam com programas e projetos para a diminuição dos índices de fracasso atingiram quase $1 / 3$ dos primeiros. Os três últimos trabalhos se voltaram para outros temas, que não puderam ser enquadrados nas duas categorias acima. No entanto, vale destacar que dois deles investigaram a formação de professores, embora os

Filosofia e Educação (Online), ISSN 1984-9605 - Volume 5, Número 2, 
resumos não permitam verificar se essa formação continuada estava sendo utilizada como meio para a diminuição ou como indicador do fracasso escolar.

\section{Considerações finais}

Pode-se constatar ao final deste balanço que as teses e dissertações com foco nos distúrbios de aprendizagem centraram-se, basicamente, em instituições do Sul-Sudeste, com proeminência para esta última, que foi responsável por praticamente $1 / 3$ de toda a produção.

Como era de se esperar, entre as áreas de estudo que abordaram o tema "dificuldades de aprendizagem", a Educação ocupa lugar privilegiado com $68,3 \%$ de toda a produção, seguida pela Psicologia (16,9\%), e a Saúde $(8,9 \%)$.

A incidência muito mais elevada das dissertações à das teses se deve, seguramente, ao tempo muito mais reduzido exigido no mestrado em comparação ao doutorado.

E, em relação aos dados sobre os procedimentos metodológicos utilizados destacou-se a incidência enorme de abordagens qualitativas $(87 \%)$.

Considerando que o cerne desta pesquisa foi a distinção entre os trabalhos que se pautaram nos distúrbios de aprendizagem como fator explicativo do fracasso escolar e os que procuraram analisar esses distúrbios, sob perspectiva crítica, ao final desta investigação pode-se afirmar que apesar das críticas produzidas sobre os primeiros, a incidência dos estudos foi mais elevada exatamente em trabalhos que se pautaram nessa perspectiva, ou seja, dos 183 trabalhos, 96 centraram-se nos distúrbios de aprendizagem como causa do baixo rendimento escolar e 85 adotaram a perspectiva crítica.

Além disso, verificamos que, dos 183 trabalhos analisados, 160 estavam concentrados no período de 1997 a 2010; 74 foram embasados pela perspectiva crítica; e 85 apoiaram-se na concepção dos distúrbios de aprendizagem como fator explicativo para o baixo rendimento escolar. Tal distribuição nos leva a concluir que, mesmo após a emergência da 
perspectiva crítica, a maior parte das produções permaneceu investigando o baixo rendimento escolar pela óptica dos distúrbios de aprendizagem.

Outro dado relevante refere-se aos dados relacionados a vertente verificada nos trabalhos realizados na USP e UNICAMP, uma vez que, embora esses tenham sido o berço da teoria crítica, ainda assim essa produção não parece ter sido suficiente para o incremento de tal perspectiva.

Cabe destacar ainda que, a área da educação foi responsável pelo maior número de estudos sobre esse assunto, dos 125 trabalhos, 67 foram pautados no fracasso escolar e 57 nos distúrbios de aprendizagem. Nas áreas da Psicologia e da Saúde, embora com números bem inferiores, não foi revelada esta mesma preferência, uma vez que apenas 11, dos 46 trabalhos defendidos, foram baseados na perspectiva crítica.

Quanto aos temas específicos, verificamos que a grande maioria dos 63 trabalhos (40, ou seja 63,5\%) adotou o conceito genérico para explicar os casos do baixo rendimento do aluno (distúrbios, dificuldades ou problemas de aprendizagem). Os outros vinte e três trabalhos se distribuíram entre problemas de comportamento, dislexia, transtornos de atenção, problemas de audição, de atraso no desenvolvimento da linguagem, epilepsia e sintomas depressivos.

Já no campo temático que utilizou outras perspectivas de análise sobre o fracasso escolar, parece haver maior precisão, já que os temas específicos não se referem, de forma geral, ao fracasso escolar, mas procuram, como indica Charlot (2000), expressões localizadas e específicas desse fracasso, como a multirrepetência, a avaliação, os efeitos da progressão continuada, entre outros.

Nesse sentido, pode-se afirmar que, apesar da emergência de estudos críticos sobre os distúrbios de aprendizagem como fator explicativo do baixo rendimento escolar, ocorrida desde o início dos anos de 1990, esta última perspectiva ainda é adotada pela maioria das produções analisadas.

Por fim, reproduzimos aqui um alerta que Warde (1993) fez, há duas décadas, sobre a pesquisa educacional: parece que o grande móvel para a produção de pesquisas e que se transforma em interlocutor são as políticas educacionais, com a produção acadêmica de um determinado campo de 
estudo (aqui representado pelo baixo rendimento escolar) exercendo menor impacto, o que pode revelar uma falta de diálogo entre os pesquisadores do campo.

Entretanto, não podemos desconsiderar que esta pesquisa foi realizada a partir dos resumos das dissertações e teses. Tais fontes possibilitaram-nos uma análise abrangente de vasta produção em largo período, mas, por isso mesmo, apresentam algumas limitações - que podem ser supridas por pesquisas futuras.

\section{Referências}

APARECIDO, Ângela Maria B. Os distúrbios de aprendizagem como categoria explicativa para o baixo rendimento escolar: revisão da literatura especializada publicada nas décadas de 60,70 e 80. 2000. Mestrado em Educação: História, Política, Sociedade. São Paulo, Pontifícia Universidade Católica de São Paulo, São Paulo.

BOURDIEU, Pierre. Os excluídos do interior. In: NOGUEIRA, Maria Alice, CATANI, Afrânio (organizadores). Escritos de educação. $9^{a}$ edição. Petrópolis, Vozes, 2007.

BRASIL. Lei no 9394, de 20 de dezembro de 1996, que estabelece as diretrizes e bases da educação nacional. Brasília, 1996.

BRASIL. MEC. Banco de teses. Brasília, Ministério da Educação -

MEC/Coordenação de Aperfeiçoamento de Pessoal de Nível Superior -

CAPES. Disponível em: http://www.capes.gov.br/servicos/banco-de-teses.

Acesso em: 12/09/2012.

CHARLOT, Bernard.. Da relação com o saber: elementos para uma teoria. Porto Alegre: ArtMed, 2000.

COLLARES Maria Cecília L.; MOYSÉS, Maria Aparecida A. 1996. Preconceitos no cotidiano escolar. ensino e medicalização. São Paulo, Cortez; Campinas, Unicamp, 1996.

MARIN, Alda Junqueira; BUENO, José Geraldo Silveira; SAMPAIO, Maria das Mercês Ferreira. Escola como objeto de estudo nos trabalhos acadêmicos brasileiros: 1981/1998. Cadernos de Pesquisa, São Paulo, vol. 35, n. 124, pp.171199, jan/abr, 2005.

MARIN, Alda Junqueira, BUENO; José Geraldo Silveira, PENNA, Marieta Gouvêa de Oliveira. Focalizando investigações sobre avaliação docente. Imagens da educação. São Paulo, v.1, nº 2, p. 89-98, 2011.

MOYSÉS, Maria Aparecida Affonso. A medicalização do não-aprender-na escola e a invenção da infância anormal. Anais da $31^{\circ}$ Reunião Anual da 
Associação Nacional de Pós-Graduação e Pesquisa em Educação - ANPEd. Caxambú, ANPEd, 2008.

PATTO, M. H. S. A produção do fracasso escolar: histórias de submissão e rebeldia. São Paulo, Casa do Psicólogo, 1999.

RODRIGUES, Zuleide B. Dificuldades de aprendiragem ou dificuldades escolares? Um estudo sobre a visão dos professores. 2009. Mestrado em Educação: História, Política e Sociedade, Pontifícia Universidade Católica de São Paulo.

ROSS, Alan O. Distúrbios psicológicos na infância: uma abordagem comportamental à teoria, pesquisa e terapêutica.. São Paulo, McGraw-Hill do Brasil, 1979.

SCHAIN, Richard J. Distúrbios de aprendizagem na criança. São Paulo, Manole, 1976.

SOUZA, Marilene de Proença R. de. Retornando à patologia para justificar a não aprendizagem escolar: a medicalização e o diagnóstico de neoliberalismo. Anais da $31^{\circ}$ Reunião Anual da Associação Nacional de Pós-Graduação e Pesquisa em Educação - ANPEd. Caxambú, ANPEd, 2008.

WARDE, Mirian Jorge. A Produção discente dos programas de pós-graduação em educação no Brasil (1982-1991). In: ASSOCIAÇÃO NACIONAL DE PÓS-GRADUAÇÃO E PESQUISA EM EDUCAÇÃO - ANPEd. Avaliação e perspectivas na área de educação. Porto Alegre, 1993.

WILLIAMS, R. 1980. Marxismo y literatura. Barcelona, Ediciones 62, 1980. 